RAD Conference Proceedings, vol. 3, pp. 159-162, 2018

ISSN 2466-4626 (online) | DOI: 10.21175/RadProc.2018.34

www.rad-proceedings.org

\title{
THORACO-ABDOMINAL TRIPHASIC CT IN ONCOLOGIC FOLLOW-UP: ASSESSMENT AND ADVANTAGES OF “LOW DOSE" PROTOCOL
}

\author{
Andrea Bonfanti ${ }^{*}$, Elena Ciortan ${ }^{2}$, Luciano Abate ${ }^{1}$, \\ Ruggero Luigi Baroni ${ }^{1}$, Serena Padelli ${ }^{1}$, Roberto Moltrasi ${ }^{1}$ \\ ${ }^{1}$ Radiographer, Department of Radiology, Casa di Cura IGEA spa, Milan, Italy \\ ${ }^{2}$ Radiologist, Department of Radiology, Casa di Cura IGEA spa, Milan, Italy
}

\begin{abstract}
The objective was to compare the contrast enhanced computed tomography (CT) "LOW DOSE" protocol for thoraco-abdominal scans, with the standard CT protocol for oncologic follow up. We analyzed these two different imaging techniques and the overall radiation dose in order to determine benefits in terms of diagnosis. We included 50 patients where oncologic follow up included a triphasic thoraco-abdominal CT for staging of liver disease. Eligibility criteria were the medical indication for a contrast-enhanced thoraco-abdominal CT as part of an oncologic follow up (breast cancer, hepatocarcinoma, neuroendocrine tumors, kidney cancer and prostatic cancer) and the availability of previous enhanced CT scans performed over the past year of follow up. The LOW DOSE protocol for triphasic CT in oncologic follow up permits saving of effective dose up to $50 \%$ (27\% on average) for each scan and an overall saving of up to $40 \%$ (15\% on average) for complete procedure in the normal BMI group. The LOW DOSE protocol was also effective in the diagnosis of thromboembolic disease. All the scans from the LOW DOSE CT protocol were analyzed by radiologists, all with at least 10 years of experience, unaware of the introduction of the protocolthere were no reported differences or difficulties in diagnosis compared to the standard CT protocol.
\end{abstract}

Key words: Effective dose, Helical Computed Tomography (CT), oncology, radiation dose reduction, triphasic technique

\section{INTRODUCTION}

Oncologic follow-up often requires close monitoring with imaging, whereby patients are exposed to an overall high radiation dose. As a result, it seems important not only to be aware of modern technologies, but also to give consideration to the radiation dose delivered to patients.

\section{MATERIALS AND METHODS}

\subsection{Study population}

Eligibility criteria were the medical indication for a contrast-enhanced thoraco-abdominal CT as part of an oncologic follow up (breast cancer, hepatocarcinoma, neuroendocrine tumors, kidney cancer and prostatic cancer) and the availability of previous enhanced CT (computed tomography) scans performed over the past year of follow up.

An analysis of prospectively collected data was performed from January to May 2017 in 50 patients where oncologic follow up included a triphasic thoracoabdominal CT for staging of liver disease.

\footnotetext{
*bonfantiandre@gmail.com
}

All patients were divided into two groups according to a normal $(15-30 \mathrm{~kg} / \mathrm{m} 2)$ or high $(>30 \mathrm{~kg} / \mathrm{m} 2)$ body mass index (BMI).

\subsection{Image technique}

All scans were performed with $128 \times$ 2-channel multidetector CT system dual source (SOMATOM Definition Flash, Siemens medical solution).

\subsection{Standard CT}

Beam collimation, 32x1.2. Pitch, 0.6 for abdomen and 1.2 for thorax. Rotation time, $0.5 \mathrm{~s}$. Software: Care Dose; Care $\mathrm{kV}$. The Scan direction is top-bottom. Reconstruction: Kernel B40 for abdomen; Kernel B30 for mediastinum; Kernel B70 for lung.

The patient was feet-first supine on the CT bed, they were connected to the Contrast Medium automatic injector.

The scan started with the bottom topogram from lung apices to femoral diaphysis. The first phase was superior abdomen precontrast. Then, bolus tracking pre-monitoring at thoraco-abdomen passage with ROI in aorta was considered independent of respiratory movements. Monitoring set at 110 HU deleted by 13 seconds from the start of injection. Auto-start on overcoming the threshold. The arterial phase (copied 
A. Bonfanti et al, Thoraco-abdominal triphasic CT in oncologic follow-up..., RAD Conf. Proc., Vol. 3, 2018, 159-162

from precontrast phase) delayed by 12 seconds from auto-start. Then, the thorax phase after 13 seconds. The hepatic venous phase delayed for 35 seconds from the thorax phase. The last phase on all abdomen was after 90 seconds.

The contrast Medium used was Ultravist 370 $\mathrm{mg} / \mathrm{ml}$. It was injected via the anterocubital vein in 1.2 $\mathrm{mL} / \mathrm{kg}$. The contrast medium technique consisted of double bolus: saline solution follows the contrast medium.

\subsection{Low dose CT}

Beam collimation, 32x1.2. Pitch, 0.6 for all scans. Rotation time, 0.5 s. Software: Care Dose; Care kV. Reconstruction: Kernel B40 for abdomen; Kernel B30 for mediastinum; Kernel B70 for lung.

The patients were feet-first supine on CT bed, and they were connected to the Contrast Medium automatic injector.

The scan started with bottom topogram from lung apices to femoral diaphysis. The first phase was superior abdomen precontrast. Then the bolus tracking pre-monitoring was performed at the thoracoabdomen passage with ROI in aorta. Monitoring was set at $95 \mathrm{HU}$ with 11 seconds of retardation from the injection. Auto-start over threshold. The arterial phase was caudo-cranial direction, from inferior renal pole to lung apices. The hepatic venous phase was after 40 seconds from the arterial phase. The last phase on all abdomen was after 120 seconds.

The contrast Medium was Ultravist $370 \mathrm{mg} / \mathrm{ml}$. It was injected via the anterocubital vein in $1.2 \mathrm{~mL} / \mathrm{kg}$. The contrast medium technique consisted of double injection: salina solution follows contrast medium.

\subsection{Difference between Standard and Low dose CT}

The most important difference between the standard CT and low dose CT was the scan direction of the arterial phase and the thorax phase.

Standard CT scans two different volumes in craniocaudal direction (liver and lung). Low dose CT scans just one unique volume (liver and lung together) in the caudo-cranial direction.

\subsection{Comparing contrast medium injection}

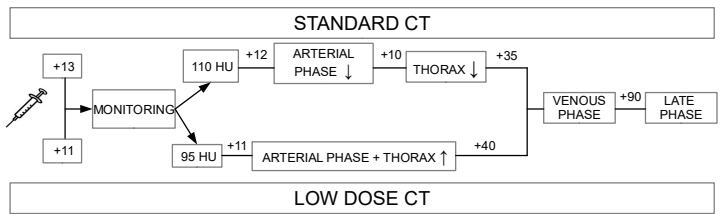

Figure 1. Thriphasic study acquisition in standard CT and low dose CT

\subsection{Radiation dose estimates}

We recorded each CT dose index per volume (CTDIvol) and dose length product (DLP) value, based on dose reports from the pictures archiving and communication system (PACS), for all phases. The effective dose should be calculated by multiplying the
DLP value by the normalized value of the conversion factor (EDLP).

In our study, there were two anatomical regions with two different EDLP ( $\mathrm{k}=0.014$ for thorax and $\mathrm{k}=0.015$ for abdomen) and the caudo-cranial thoracoabdomen scan provided a unique DLP value despite the existence of two different regions. To obtain an estimated value to the conversion we used $\mathrm{EDLP}=0.0145$, the average between EDLP for thorax and abdomen.

\section{RESULTS}

\subsection{Radiation dose estimates}

We classified two types of comparison: Total body scan, which analyzed all CT exams (with all phases); and Single scan, which only analyzed the difference between the caudo-cranial and the cranio-caudal thoraco-abdomen phase.

The table with the dosimetric references of the two CT methods described is shown below. The values of the effective dose $\mathrm{E}(\mathrm{mSv})$ were calculated according to what was described in the previous paragraph. It is emphasized that the comparison between the CT methods occurred on the same patients.

\subsection{Total body}

Table 1. Effective dose (E) and dose saving rate for the entire Total Body CT for $15<\mathrm{BMI}<30$ $15<\mathrm{BMI}<30$

\begin{tabular}{|c|c||c||c|c||c||c|}
\hline $\begin{array}{c}\text { Pati } \\
\text { ent }\end{array}$ & $\begin{array}{c}\text { BMI } \\
\left(\mathbf{k g} / \mathbf{m}^{\mathbf{2}}\right)\end{array}$ & $\begin{array}{c}\text { DLPP } \\
\text { old }\end{array}$ & $\begin{array}{c}\text { DLP } \\
\text { new }\end{array}$ & $\begin{array}{c}\text { E old } \\
(\mathbf{m S v})\end{array}$ & $\begin{array}{c}\text { E new } \\
(\mathbf{m S v})\end{array}$ & \% \\
\hline 2 & 17.4 & 1002 & 732 & 14.5 & 10.6 & 26.9 \\
\hline 3 & 19.1 & 1338 & 1020 & 19.4 & 14.8 & 19.4 \\
\hline 5 & 20.2 & 1406 & 850 & 20.4 & 12.3 & 39.5 \\
\hline 25 & 13.7 & 792 & 774 & 11.5 & 11.2 & 2.3 \\
\hline 28 & 20.6 & 1286 & 883 & 18.7 & 12.1 & 35.2 \\
\hline 38 & 19.5 & 991 & 973 & 14.4 & 14.1 & 1.8 \\
\hline 40 & 19.8 & 1027 & 983 & 14.9 & 14.3 & 4.3 \\
\hline 42 & 20.8 & 1344 & 1138 & 19.5 & 16.5 & 15.3 \\
\hline 45 & 19.6 & 923 & 821 & 13.4 & 11.9 & 11.1 \\
\hline 48 & 19.6 & 1163 & 1009 & 16.9 & 14.6 & 13.2 \\
\hline 51 & 19.6 & 1058 & 976 & 15.3 & 14.2 & 7.8 \\
\hline 53 & 19.8 & 1597 & 1167 & 23.2 & 16.9 & 27.0 \\
\hline 1 & 23.1 & 1028 & 925 & 15.0 & 13.4 & 10.0 \\
\hline 8 & 24.7 & 1671 & 1609 & 24.2 & 23.3 & 3.7 \\
\hline 9 & 25.0 & 1474 & 1122 & 21.4 & 16.3 & 23.9 \\
\hline 14 & 24.7 & 1295 & 1242 & 18.8 & 18.0 & 4.1 \\
\hline 20 & 21.4 & 1128 & 1085 & 16.4 & 15.8 & 3.8 \\
\hline 22 & 22.5 & 1676 & 1377 & 24.3 & 20.0 & 17.8 \\
\hline 23 & 23.6 & 1352 & 1109 & 19.6 & 16.1 & 18.0 \\
\hline 33 & 24.1 & 1411 & 1033 & 20.5 & 15.0 & 26.8 \\
\hline 34 & 22.7 & 1389 & 1192 & 20.1 & 17.3 & 14.2 \\
\hline
\end{tabular}


A. Bonfanti et al, Thoraco-abdominal triphasic CT in oncologic follow-up..., RAD Conf. Proc., Vol. 3, 2018, 159-162

\begin{tabular}{|c|c|c|c||c|c|c|}
\hline $\begin{array}{c}\text { Pati } \\
\text { ent }\end{array}$ & $\begin{array}{c}\text { BMI } \\
\left(\mathbf{k g} / \mathbf{m}^{\mathbf{2}}\right)\end{array}$ & $\begin{array}{c}\text { DLP } \\
\text { old }\end{array}$ & $\begin{array}{c}\text { DLP } \\
\text { new }\end{array}$ & $\begin{array}{c}\text { E old } \\
\text { (mSv) }\end{array}$ & $\begin{array}{c}\text { E new } \\
\text { (mSv) }\end{array}$ & \% \\
\hline 37 & 24.7 & 2382 & 2157 & 34.5 & 31.3 & 9.5 \\
\hline 39 & 21.7 & 1401 & 1192 & 20.3 & 17.3 & 15.0 \\
\hline 43 & 22.1 & 1112 & 896 & 16.1 & 13.0 & 19.4 \\
\hline 44 & 23.8 & 1475 & 1363 & 21.4 & 19.8 & 7.6 \\
\hline 47 & 23.6 & 1403 & 1344 & 20.3 & 19.5 & 4.2 \\
\hline 54 & 23.5 & 1526 & 1178 & 22.1 & 17.1 & 22.1 \\
\hline 6 & 26.3 & 1379 & 1305 & 20.0 & 18.9 & 5.4 \\
\hline 7 & 26.1 & 1701 & 1531 & 24.7 & 22.2 & 10.0 \\
\hline 16 & 25.8 & 1628 & 1302 & 23.6 & 18.9 & 20.0 \\
\hline 19 & 28.9 & 1790 & 1546 & 26.0 & 22.4 & 13.6 \\
\hline 21 & 25.7 & 1587 & 1417 & 23.0 & 20.6 & 10.7 \\
\hline 29 & 27.3 & 1902 & 1676 & 27.6 & 24.3 & 11.9 \\
\hline 30 & 27.0 & 1693 & 1388 & 24.6 & 20.1 & 18.0 \\
\hline 31 & 25.0 & 1311 & 1181 & 19.0 & 17.1 & 9.9 \\
\hline 35 & 26.8 & 1516 & 1296 & 22.0 & 18.8 & 14.5 \\
\hline 41 & 27.0 & 1403 & 1016 & 20.3 & 14.7 & 27.6 \\
\hline 46 & 29.7 & 1483 & 1157 & 21.5 & 16.8 & 22.0 \\
\hline 49 & 25.0 & 1319 & 1101 & 19.1 & 16.0 & 16.5 \\
\hline 52 & 28.0 & 1586 & 1397 & 23.0 & 20.3 & 11.9 \\
\hline AVG & & $\mathbf{1 3 9 8}$ & $\mathbf{1 1 8 6}$ & $\mathbf{2 0 . 3}$ & $\mathbf{1 7 . 2}$ & $\mathbf{1 5 . 2} \%$ \\
\hline
\end{tabular}

Table 2. Effective dose (E) and dose saving rate for the entire Total Body CT for BMI $>30$

$\mathrm{BMI}>30$

\begin{tabular}{|c|c|c||c|c|c||c|}
\hline $\begin{array}{c}\text { Pati } \\
\text { ent }\end{array}$ & $\begin{array}{c}\text { BMI } \\
(\mathbf{k g} / \mathbf{m 2})\end{array}$ & $\begin{array}{c}\text { DLP } \\
\text { old }\end{array}$ & $\begin{array}{c}\text { DLP } \\
\text { new }\end{array}$ & $\begin{array}{c}\text { E old } \\
(\mathbf{m S v})\end{array}$ & $\begin{array}{c}\text { E new } \\
\mathbf{( m S v )}\end{array}$ & \% \\
\hline 4 & 35.7 & 3393 & 2945 & 49.2 & 42.7 & 13.2 \\
\hline 10 & 32.4 & 2653 & 2287 & 38.5 & 33.2 & 13.8 \\
\hline 27 & 32.9 & 2999 & 2211 & 43.5 & 32.1 & 26.3 \\
\hline 31 & 32.5 & 2000 & 1471 & 29.0 & 21.3 & 26.5 \\
\hline 55 & 38.0 & 5360 & 2795 & 77.7 & 40.5 & 47.9 \\
\hline 56 & 30.4 & 1840 & 1571 & 26.7 & 22.8 & 14.6 \\
\hline AVG & & $\mathbf{3 0 4 0}$ & $\mathbf{2 2 1 3}$ & $\mathbf{4 4 . 1}$ & $\mathbf{3 2 . 1}$ & $\mathbf{2 7 . 2} \%$ \\
\hline \hline
\end{tabular}

Below is a histogram showing the effective dose $\mathrm{E}$ (mSv) between the two compared protocols based on the BMI classes.

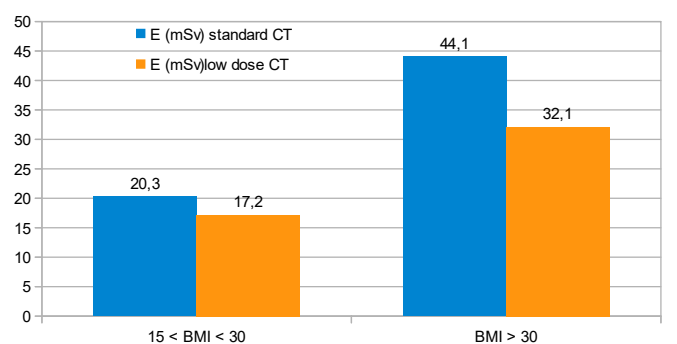

Figure 2. Effective dose $\mathrm{E}(\mathrm{mSv})$ for standard CT (blue) and low dose CT (orange)

\subsection{Single scan}

Table 3. Effective dose (E) and percentage of dose saving in thoraco-abdomen scan for $15<\mathrm{BMI}<30$ $15<\mathrm{BMI}<30$

\begin{tabular}{|c|c|c|c|c|c|c|}
\hline $\begin{array}{c}\text { Patie } \\
\text { nt }\end{array}$ & $\underset{(\mathrm{kg} / \mathrm{m} 2)}{\text { BMI }}$ & $\begin{array}{l}\text { DLP } \\
\text { A+T }\end{array}$ & $\begin{array}{l}\text { DLP 1 } \\
\text { scan }\end{array}$ & $\begin{array}{l}\text { E A+T } \\
\text { (mSv) }\end{array}$ & $\begin{array}{c}\text { E 1 scan } \\
\text { (mSv) }\end{array}$ & $\%$ \\
\hline 2 & 17.4 & $114+143$ & 188 & 3.7 & 2.7 & 27.1 \\
\hline 3 & 19.1 & $189+167$ & 219 & 5.6 & 3.2 & 38.4 \\
\hline 5 & 20.2 & $305+167$ & 242 & 6.8 & 3.5 & 48.2 \\
\hline 25 & 13.9 & $118+103$ & 193 & 3.2 & 2.8 & 12.5 \\
\hline 28 & 20.6 & $193+221$ & 207 & 6.0 & 3.0 & 50.1 \\
\hline 38 & 19.5 & $163+149$ & 254 & 4.5 & 3.7 & 18.5 \\
\hline 40 & 19.8 & $164+171$ & 272 & 4.9 & 3.9 & 18.9 \\
\hline 42 & 20.8 & $181+213$ & 304 & 5.7 & 4.4 & 23.1 \\
\hline 45 & 19.6 & $130+145$ & 243 & 4.0 & 3.5 & 11.8 \\
\hline 48 & 19.6 & $160+185$ & 311 & 5.0 & 4.5 & 10.1 \\
\hline 51 & 19.6 & $132+179$ & 279 & 4.5 & 4.1 & 10.8 \\
\hline 53 & 19.8 & $271+204$ & 288 & 6.9 & 4.2 & 39.1 \\
\hline 1 & 23.1 & $158+165$ & 213 & 4.7 & 3.1 & 34.1 \\
\hline 8 & 24.7 & $251+269$ & 467 & 7.6 & 6.8 & 10.3 \\
\hline 9 & 25.0 & $334+222$ & 308 & 8.0 & 4.5 & 44.2 \\
\hline 14 & 24.7 & $186+197$ & 313 & 5.6 & 4.5 & 18.4 \\
\hline 20 & 21.4 & $180+168$ & 288 & 5.0 & 4.2 & 17.1 \\
\hline 22 & 22.5 & $241+222$ & 330 & 6.7 & 4.8 & 28.6 \\
\hline 23 & 23.7 & $199+210$ & 307 & 5.9 & 4.5 & 25.0 \\
\hline 33 & 24.1 & $194+217$ & 269 & 6.0 & 3.9 & 34.7 \\
\hline 34 & 22.7 & $201+212$ & 281 & 6.0 & 4.1 & 32.0 \\
\hline 37 & 24.7 & $586+276$ & 617 & 12.1 & 9.0 & 26.0 \\
\hline 39 & 21.7 & $212+165$ & 268 & 5.4 & 3.9 & 28.6 \\
\hline 43 & 22.0 & $165+179$ & 234 & 5.0 & 3.4 & 32.8 \\
\hline 44 & 23.8 & $238+223$ & 400 & 6.7 & 5.8 & 13.1 \\
\hline 47 & 23.6 & $137+171$ & 269 & 4.5 & 3.9 & 13.0 \\
\hline 54 & 23.5 & $300+153$ & 288 & 6.5 & 4.2 & 35.7 \\
\hline 6 & 26.3 & $277+221$ & 379 & 7.2 & 5.5 & 23.6 \\
\hline 7 & 26.1 & $264+264$ & 404 & 7.7 & 5.9 & 23.5 \\
\hline 16 & 25.8 & $259+250$ & 369 & 7.4 & 5.4 & 27.5 \\
\hline 19 & 28.9 & $276+268$ & 384 & 7.9 & 5.6 & 29.4 \\
\hline 21 & 25.7 & $257+246$ & 366 & $7 \cdot 3$ & $5 \cdot 3$ & 27.2 \\
\hline 29 & 27.9 & $250+213$ & 372 & 6.7 & 5.4 & 19.4 \\
\hline 30 & 27.0 & $249+250$ & 350 & 7.2 & 5.1 & 29.9 \\
\hline 31 & 25.0 & $210+177$ & 287 & 5.6 & 4.2 & 25.6 \\
\hline 35 & 26.8 & $254+219$ & 334 & 6.8 & 4.8 & 29.2 \\
\hline 41 & 27.0 & $299+234$ & 387 & 7.7 & 5.5 & 28.8 \\
\hline 46 & 29.7 & $236+257$ & 326 & 7.2 & 4.7 & 34.0 \\
\hline 49 & 25.0 & $308+165$ & 284 & 6.8 & 4.1 & 39.3 \\
\hline 52 & 28.0 & $227+201$ & 335 & 6.2 & 4.9 & 21.6 \\
\hline AVG & & & & 6.2 & 4.5 & $27.3 \%$ \\
\hline
\end{tabular}


A. Bonfanti et al, Thoraco-abdominal triphasic CT in oncologic follow-up..., RAD Conf. Proc., Vol. 3, 2018, 159-162

Table 4. Effective dose (E) and percentage of dose savings in thoraco-abdomen scans for $\mathrm{BMI}>30$ $\mathrm{BMI}>30$

\begin{tabular}{|c|c||c|c|c|c|c|}
\hline $\begin{array}{c}\text { Patien } \\
\mathbf{t}\end{array}$ & $\begin{array}{c}\text { BMI } \\
(\mathbf{k g} / \mathbf{m} 2)\end{array}$ & DLP A+T & $\begin{array}{c}\text { DLP 1 } \\
\text { scan }\end{array}$ & $\begin{array}{c}\text { E A+T } \\
(\mathbf{m S v})\end{array}$ & $\begin{array}{c}\text { E 1 } \\
\mathbf{s c a n} \\
(\mathbf{m S v})\end{array}$ & $\%$ \\
\hline 4 & $35 \cdot 7$ & $603+524$ & 769 & 16.3 & 11.2 & 31.6 \\
\hline 10 & 32.4 & $490+338$ & 607 & 11.9 & 8.8 & 26.2 \\
\hline 27 & 32.9 & $554+402$ & 579 & 13.8 & 8.4 & 39.1 \\
\hline 32 & 32.5 & $360+304$ & 357 & 9.6 & 5.2 & 46.1 \\
\hline 55 & 38.0 & $1080+667$ & 686 & 25.1 & 10.0 & 60.4 \\
\hline 56 & 30.4 & $274+230$ & 340 & 7.3 & 4.9 & 32.3 \\
\hline AVG & & & & $\mathbf{1 4 . 0}$ & $\mathbf{8 . 1}$ & $\mathbf{4 2 . 4 \%}$ \\
\hline \hline
\end{tabular}

Below is a histogram showing the effective dose $\mathrm{E}(\mathrm{mSv})$ between the two compared protocols based on the BMI classes.

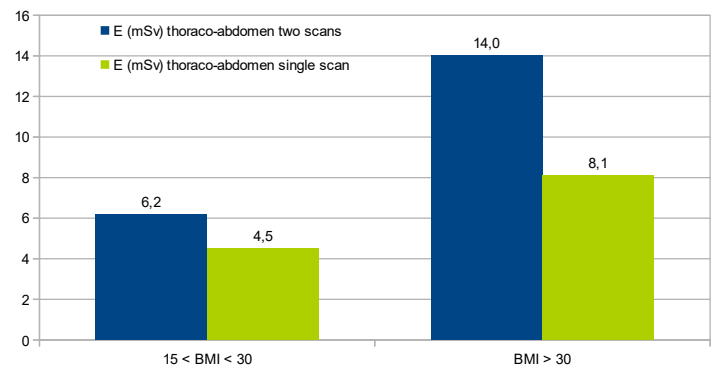

Figure 3. Effective Dose E (mSv) for thoraco-abdominal two scans for standard CT (blue) and thoraco-abdominal single scan for low dose CT (green)

\subsection{Image analysis}

The images obtained with the low dose CT were reported by radiologists with at least 10 years of experience without knowledge of the introduction of the low dose CT scan (one blind): the radiologists did not report any differences and/or diagnostic difficulties.

\subsection{Thromboembolic disease}

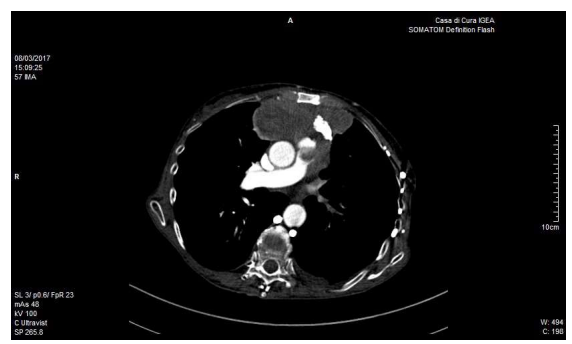

Figure 4. Mediastinal mass infiltrating pulmonary artery

The caudo-cranial scan was obtained to acquire all thoraco-abdominal volume in \pm 12 seconds. The delay from the injection of 11 seconds allows the study of thorax volume at the fortieth second, ideal to study both the parenchyma and mediastinum $(\mathrm{M}+)$ and the arterial vascular tree (TPE).

\section{CONCLUSION}

The Low Dose protocol for triphasic CT in oncologic follow up permits saving of effective dose of up to $50 \%$ (27\% on average) for each scan and an overall saving of up to $40 \%$ ( $15 \%$ on average) for the complete procedure in the normal BMI group. The Low Dose protocol is also efficient in the diagnosis of the thromboembolic disease.

All the scans from the Low Dose CT protocol were analyzed by radiologists, all with at least 10 years of experience, unaware of the introduction of the protocol. There were no reports of any differences or difficulties in diagnosis compared to the standard CT protocol.

\section{REFERENCES}

1. Recommendations of the International Commission on Radiological Protection, ICRP Publication 103, Ottawa, Canada, 2007.

Retrieved from: http://www.icrp.org/docs/ICRP Publi cation 103-Annals of the ICRP 37(2-4)-

Free extract.pdf;

Retrieved on: Jun. 19, 2018

2. European Commission. (Feb. 18, 2000). European guidelines of quality criteria for computed tomography.

Retrieved from: https://publications.europa.eu/en/pub lication-detail/-/publication/d229c9e1-a967-49deb169-59ee68605f1a;

Retrieved on: Jun. 19, 2018

3. Basic anatomical and physiological data for use in radiological protection, ICRP Publication 89, ICRP, Ottawa, Canada, 2002.

PMid: 14506981

4. Relative biological effectiveness (RBE), quality factor $(Q)$, and radiation weighting factor $(w R)$, ICRP Publication 92, ICRP, Ottawa, Canada, 2002.

PMid: 14614921

5. Low dose extrapolation of radiation-related cancer risk, ICRP Publication 99, ICRP, Ottawa, Canada, 2005.

DOI: 10.1016/j.icrp.2005.11.002

PMid: 16782497

6. Assessing dose of the representative person for the purpose of radiation protection of the public and the optimisation of radiological protection: Broadening the process, ICRP Publication 101, ICRP, Ottawa, Canada, 2006.

DOI: 10.1016/j.icrp.2006.09.003

PMid: 17174713

7. G. Starck, L. Lonn, et al., "A method to obtain the same levels of CT image noise for patients of various size, to minimize radiation dose," $B r$. J. Radiol., vol. 75, no. 890, pp. 140 - 150, Feb. 2002.

DOI: $10.1259 /$ bjr. 75.890 .750140

PMid: 11893638

8. C. S. Alvin, J. L. Holly et al., "Innovation in CT Dose Reduction Strategy: Application of the Adaptive Statistical Iterative Reconstruction Algorithm," Am. J. Roentgenol., vol. 194, no. 1, pp. 191 - 199, Jan. 2010.

DOI: 10.2214/AJR.09.2953

PMid: 20028923 